\title{
Human skeletal muscles replaced to a high degree by white adipose tissue
}

\author{
By
Keisuke INA ${ }^{1}$, Hirokazu KITAMURA ${ }^{1}$, Takayuki MASAKI ${ }^{2}$, Shuji TATSUKAWA ${ }^{1}$, Hironobu YOSHIMATSU ${ }^{2}$ and Yoshihisa FUJIKURA ${ }^{1}$ \\ ${ }^{1}$ Department of Molecular Anatomy, Faculty of Medicine, Oita University \\ ${ }^{2}$ Department of Internal Medicine 1, Faculty of Medicine, Oita University, \\ 1-1, Idaigaoka, Hasama-machi, Yufu, Oita, 879-5593, Japan
}

- Received for Publication, August 28, 2010-

Key Words: fatty degeneration, skeletal muscle, diabetes mellitus, renal failure, hypothyroidism

\begin{abstract}
Summary: Extreme replacement of skeletal muscles by adipose tissue was found in an 86-year old Japanese male cadaver during dissection practice for medical students at Oita University School of Medicine. Especially, the bilateral sartorius muscles looked overall like adipose tissue. The man had suffered from diabetes mellitus, renal failure, hypertension and hypothyroidism before his death. He was also an alcohol drinker. He had been bedridden late in life. The cause of death was renal failure. In microscopy, the adipose tissue-like sartorius muscle was shown to consist of leptin-positive adipocytes with a small number of degenerated muscle fibers. Fatty replacement, or fatty degeneration, appears to result from endocrine and metabolic disorders, and being bedridden leads to muscle atrophy and damage, although the origin of the adipocytes which emerged in the degenerated muscles is unknown.
\end{abstract}

\section{Introduction}

There are two distinct types of fat accumulation in skeletal muscles: intramyocellular fat deposits and extramyocellular adipocyte accumulation. The former usually results from an insulin-resistant status, such as obesity and type-2 diabetes mellitus (Virkamaki et al., 2001 ${ }^{1)}$; Goodpaster et al., 2004 $4^{2}$ ). In those cases, triglycerides are thought to accumulate in muscle fibers because the uptake of free fatty acids into the muscle fibers is increased and fatty acid oxidation is repressed. The latter may be ascribed to fatty degeneration after muscle atrophy and injury. It has been known that neurogenic amyotrophy, such as amyotrophic lateral sclerosis (Hamano et al., 2004 ${ }^{33}$ ) or denerved muscle atrophy (Dulor et al., $1998^{4)}$ ), and myopathies including muscular dystrophy (Banker et al., 2004 $4^{5}$ ) and mitochondrial myopathy $\left(\right.$ Olsen et al., $\left.2003^{6}\right)$ as well as acquired endocrine or metabolic disorders (Khaleeli et al., 19837); Bailey et al., $1996^{8}$; Merforth et al., 1999 ${ }^{97}$ ) are accompanied by fatty degeneration, or adipocyte accumulation. A muscle has been demonstrated to be almost entirely replaced by adipocytes in a case of Duchenne muscular dystrophy (Banker et al., 2004 $4^{5)}$ and in rabbits with the experimen- tally denerved muscle atrophy (Dulor et al., 19984).

A recent report has demonstrated that, when a muscle is injured, the event which subsequently occurs is either myocyte regeneration or fatty degeneration, depending on the difference in the stimulus, i.e., cardiotoxin or glycerol, respectively (Uezumi et al., 2010 ${ }^{10)}$ ). In the case of fatty degeneration, the proliferation of myogenic progenitor cells, or satellite cells, was repressed, whereas adipogenic progenitors proliferated and differentiated into adipocytes, although the mechanism remained to be determined. These adipogenic progenitors were revealed to be present in the interstitium of the muscle tissue, and were characterized by the expression of platelet-derived growth factor receptor $\alpha$ (PDGFR $\alpha$ ).

In the present paper, we report a case with a high replacement of muscle by fat, and discuss the type and mechanism of fat accumulation in skeletal muscles.

\section{Case report}

During cadaveric dissection practice for medical students at Oita University in 2008, we came across skeletal muscles almost entirely replaced by fat in the cadaver of 
an 86-year old man of Japanese origin. The man had suffered from diabetes mellitus, renal failure due to diabetic nephropathy, hypertension and hypothyroidism before his death. All of these diseases were uncontrolled (Table 1) without respect to medication, including the oral hypoglycemic agent (SU), the angiotensin-converting enzyme inhibitor, the calcium antagonist, the $\alpha$ blocker and the thyroid hormone agent. He had been an alcohol drinker and bedridden late in life. The cause of death was judged to be renal failure.

The cadaver was fixed by injection of $10 \%$ formaldehyde (10\% volume/weight) into the femoral artery 30 to 60 hours after death, followed by alcohol replacement.

The protocol for the present research did not include any specific issues that required approval from the ethics committees of Oita University, and conformed to the provisions of the Declaration of Helsinki of 1995 (revised in Edinburgh in 2000).

\section{Methods}

\section{Specific gravity of tissues}

The specific gravity of the tissues was determined depending on whether they floated or sank in saline.

\section{$H E$ and specific staining}

In the histopathological examination, conventional hematoxylin-eosin and Azan staining were performed.

\section{Immunohistochemistry}

White adipose tissues (WAT) and muscles were removed and postfixed in 4\% para-formaldehyde. The tissues were embedded in paraffin, and the WAT and muscles $(5 \mu \mathrm{m})$ were cut using a vibrotome (Lintech Co., Oita, Japan). The tissues were washed three times in PBS and incubated for $1 \mathrm{~h}$ in a solution of blocking peptide. The slices were then transferred without rinsing to the primary antibody solution consisting of rabbit polyclonal $\mathrm{Ob}$ antibody (sc-842 Santa Cruz Biotechnology, Inc., Santa Cruz, CA), which is used for the detection of precursor and mature $\mathrm{Ob}$ (leptin) of human origin in im-

Table 1. Clinical data of one month before the case's death

\begin{tabular}{lrl}
\hline BMI & 22 & $(<22.0)$ \\
BP & $190 / 95 \mathrm{mmHg}$ & $(<140 / 90)$ \\
BS & $225 \mathrm{mg} / \mathrm{dl}$ & \\
BUN & $92.1 \mathrm{mg} / \mathrm{dl}$ & $(8-20)$ \\
$\mathrm{Cr}$ & $5.2 \mathrm{mg} / \mathrm{dl}$ & $(0.4-1.0)$ \\
$\mathrm{T}-\mathrm{chol}$ & $112 \mathrm{mg} / \mathrm{dl}$ & $(130-230)$ \\
TG & $73 \mathrm{mg} / \mathrm{dl}$ & $(50-150)$ \\
CPK & $36 \mathrm{u} / 1$ & $(44-210)$ \\
TSH & $72.7 \mu \mathrm{IU} / \mathrm{ml}$ & $(0.4-4.0)$ \\
FT3 & $1.4 \mathrm{pg} / \mathrm{ml}$ & $(2.2-4.1)$ \\
FT4 & $0.6 \mathrm{ng} / \mathrm{ml}$ & $(0.8-1.9)$ \\
\hline
\end{tabular}

The parenthesized numbers are the normal ranges of the clinical data. munohistochemistry (dilution range 1:100). After $24 \mathrm{~h}$ of incubation on ice, the slices were washed three times in PBS and processed by the ABC method. The slices were transferred to a biotinylated anti-rabbit antibody (Vector Laboratories, Burlingame, CA) solution for $2 \mathrm{~h}$, washed, transferred to avidin-biotinylated peroxidase for $2 \mathrm{~h}$, washed, and then developed with diaminobenzidine substrate for $10 \mathrm{~min}$. The slices were then washed, mounted on slides, and coverslipped with Permount.

\section{Results}

The bilateral sartorius muscles looked overall like adipose tissue (Fig. 1). To a lesser extent, the quadriceps femoris muscles and rectus abdominis muscles were also replaced by yellowish fat-like tissue.

The specific gravity of the sartorius muscle in the present case was much smaller than that of an age- and body weight-matched male subject, and similar to that of adipose tissue (Fig. 2).

The non-stained areas, representing adipose tissue, ac-

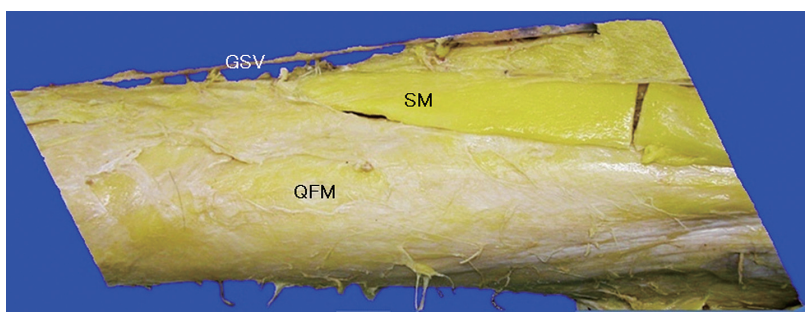

Fig. 1. Anterior view of the left thigh. A sartorius muscle cut off is seen in the figure. It has a yellowish appearance, just like adipose tissue. SM, sartorius muscle; GSV, great saphenous vein; QFM, quadriceps femoris muscle.

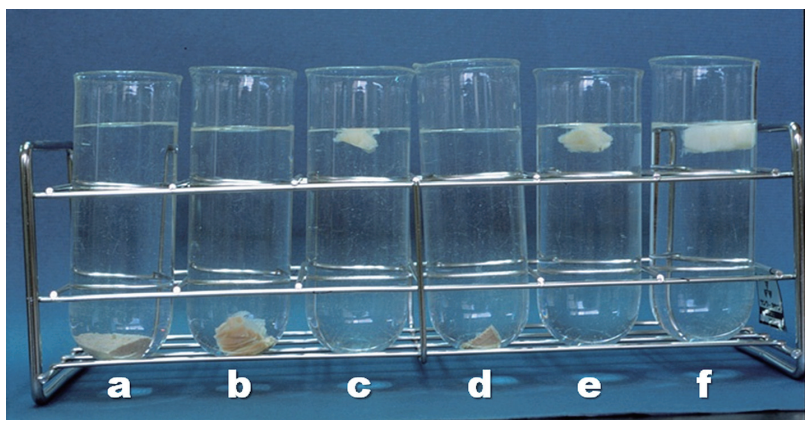

Fig. 2. Specific gravity of each tissue. $(a, b, c)$ Tissue of the control male subject. (d,e,f) The present case. Liver $(a, d)$, sartorius muscle $(b, e)$, and subcutaneous adipose tissue $(c, f)$ in saline. The sartorius muscle of the present case floats in saline, similarly to subcutaneous adipose tissue. 
counted for the majority of the HE-stained cross section of the sartorius muscle of the present case, in contrast to that of the control subject (Fig. 3). In microscopy, almost the entire area of the muscle was found to be occupied by adipocytes (Fig. 4A). Connective tissue with abundant collagen fibers divided the adipose tissue into distinct areas (Figs. 3, 4A, 4B). In Azan staining, the constituents stained in red were surrounded by collagen fibers (blue) in some areas of the connective tissue (Fig. 5). The adipocytes were similar in size to subcutaneous adipocytes (Fig. 6). They possessed a single locular fat droplet and a single nucleus (Fig. 6A). Capillaries appeared to be more abundant around the adipocytes than in the subcutaneous adipose tissue (Fig. 6A). Cells with multiple nuclei in the central area, or myotubular cells, were not found. On

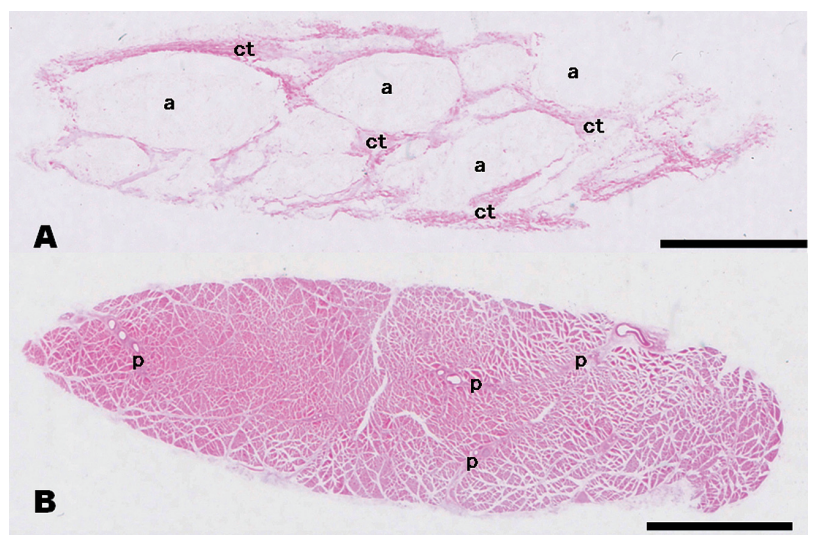

Fig. 3. HE staining of the cross section of the sartorius muscle. (A) The present case. (B) The control subject. The sartorius muscle is occupied by non-stained areas, representing adipose tissue (a) (A). Eosinophilic tissue, or connective tissue (ct), is shown to divide the adipose tissue (A). p, perimysium. Bar: $5 \mathrm{~mm}$. the other hand, fatty liver was not recognized in this case (data not shown).

Figure 7 shows the result of indirect immunostaining for leptin. Adipocytes in the sartorius muscles were revealed to be positive, corresponding to the adipocytes in the subcutaneous tissue (Figs. 7A, 7B). The sartorius muscles of the control subject were negative for leptin (Fig. 7C).

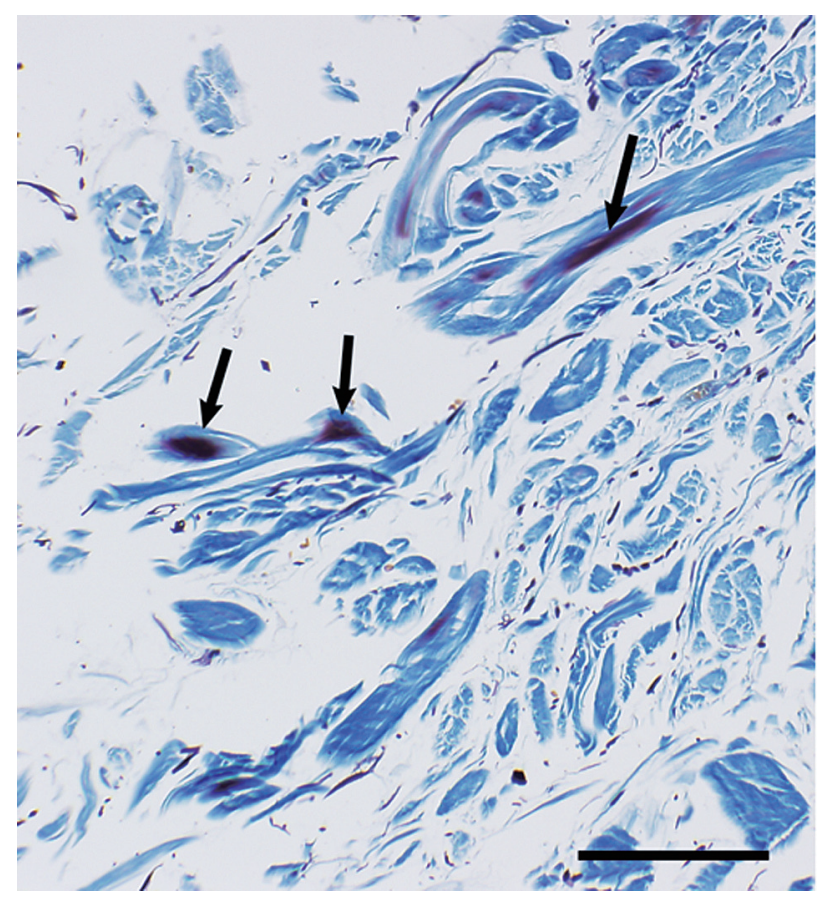

Fig. 5. Azan staining of a cross section of the sartorius muscle from the present case. Red-stained constituents (arrows) surrounded by collagen fibers (blue) are seen. Bar: $50 \mu \mathrm{m}$.
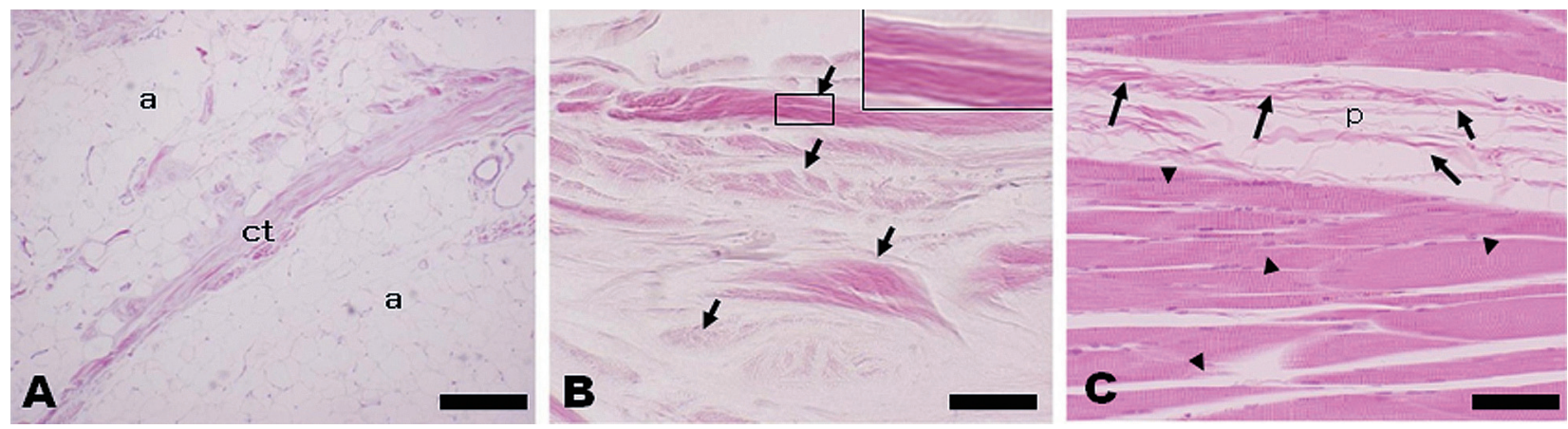

Fig. 4. HE staining of the longitudinal section of the sartorius muscle. (A, B) The present case. (C) The control subject. The sartorius muscle is occupied by adipose tissue (a) (A). Connective tissue (ct) containing abundant collagen fibers (arrows, inset $\times 3.8$ ) is seen between areas of adipose tissue (A, B). Intact striated structures (arrowheads) are seen in the muscle fibers of the control subject (C). p, perimysium. Bar: (A) $100 \mu \mathrm{m},(\mathrm{B}, \mathrm{C}) 50 \mu \mathrm{m}$. 

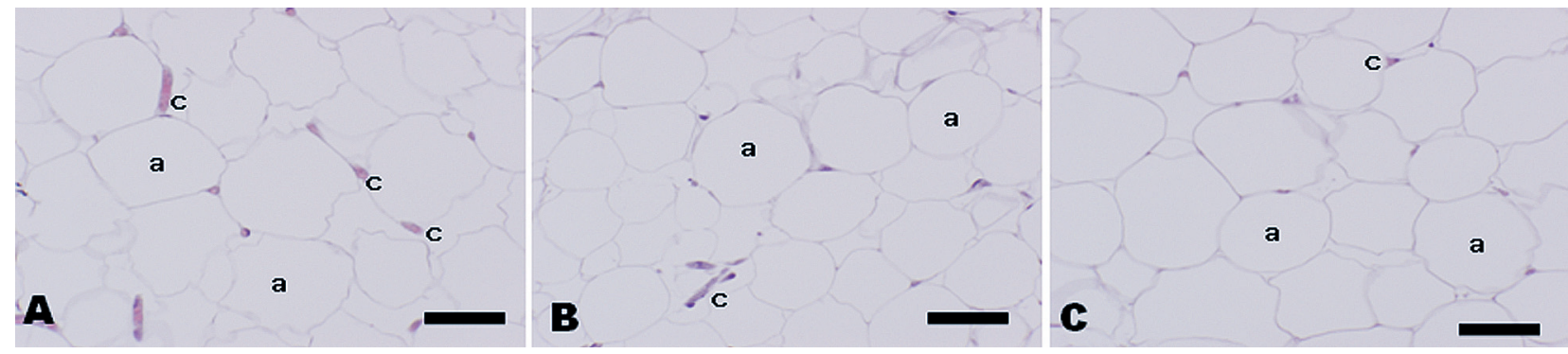

Fig. 6. Adipocytes of each organ. (A) The adipose tissue which newly emerged in the sartorius muscle of the present case. (B) Subcutaneous adipose tissue of the case. (C) Subcutaneous adipose tissue of the control subject. The adipocytes reveal no morphological differences among the three kinds of adipose tissue. a, adipocyte; c, capillary. Bar: $50 \mu \mathrm{m}$.
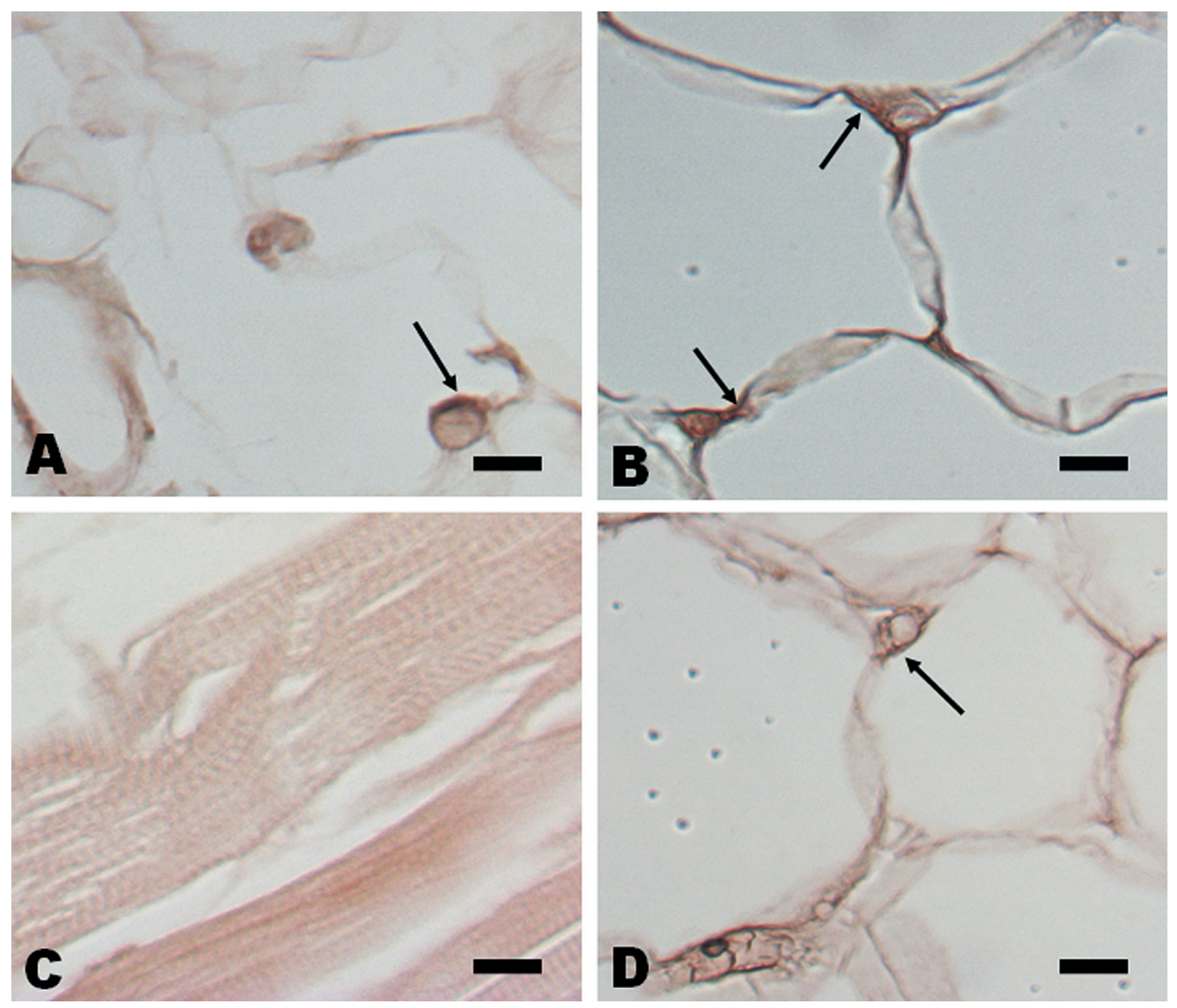

Fig. 7. Immunostaining for leptin in each tissue. Leptin is stained with the anti-leptin antibody by the immunoperoxidase method. (A, B) The present case. (C, D) The control subject. (A, C) Sartorius muscle. (B, D) Subcutaneous adipose tissue. The perikarion areas (arrows) of the adipocytes are stained positive in the sartorius muscle of the present case (A), as well as the subcutaneous adipocytes. The sartorius muscle fibers are negative for staining (C). Bar: $10 \mu \mathrm{m}$.

\section{Discussion}

We addressed a rare case in which a skeletal muscle was almost entirely replaced by fat. In microscopy, the sartorius muscle of the present case was occupied to an extreme degree by adipocytes. Although the connective tissue with abundant collagen fibers dividing the adipose tissue was considered to correspond to the perimysium, it may be involved, at least in part, in fibrosis. Also, the Azan red-stained constituents appeared to be degenerated myocytes. The morphology of the adipocytes was quite similar to that of subcutaneous adipocytes in terms of cell size and numbers of the fat droplets and the nuclei in 
each cell. Skeletal myocytes are much longer than adipocytes and possess more than one nucleus. Furthermore, leptin, which is a marker of adipocytes, was detected in the adipocytes by immunostaining. Taken together, these findings suggest that the fat accumulated in the muscle of the case was not intramyocellular, but belonged to adipocytes which emerged in the extramyocellular space.

It is well known that, when a skeletal muscle is damaged, it undergoes fatty degeneration in some diseases, including neurogenic amyotrophy (Dulor et al., 1998); Hamano et al., 2004 ${ }^{3)}$ ) and myopathy (Khaleeli et al., 19837); Bailey et al., 1996 ${ }^{8}$; Merforth et al., 19999); Olsen et al., 20036); Banker et al., 2004 ${ }^{5)}$ ). The present case had suffered from uncontrolled diabetes mellitus, renal failure and hypothyroidism before death. The man had also been an alcohol drinker and had been bedridden late in life. These factors and aging conceivably contributed to the muscle damage. It has been reported that the activity of proteasomes was increased and resulted in muscle protein breakdown in experimental diabetic animals (Merforth et al., 1999 ${ }^{9}$ ). Neurogenic amyotrophy may also yield due to diabetic neuropathy. In renal failure, muscle waste was shown to be induced by increasing proteasome activation and decreasing protein synthesis (Bailey et al., 1996 ${ }^{8)}$ ). It is well known that myopathy occurs in hypothyroidism (Khaleeli et al., 19837). Alcohol drinking is a factor to induce rhabdomyolysis. It may also generate neurogenic amyotrophy. Being bedridden for a long time leads to muscle atrophy through muscle disuse. Fat replacement of muscles due to aging is known as "sarcopenia" (Visser et al., 2005 ${ }^{11)}$ ).

Where did the damaged muscle fibers go? In general, it is considered that they undergo phagocytosis by macrophages.

Where did the newly emerged adipocytes derive from? There are a variety of reports concerning the origin of these adipocytes, including mesenchymal progenitors (Joe et al., 2010²); Uezumi et al., 2010 ${ }^{10)}$ ), pericytes (Farrington-Rock et al., 2004 ${ }^{13)}$ ), macrophages (Yamanouchi et al., 2006 ${ }^{14)}$ ), satellite cells (Xaymardan et al., $2002^{15)}$ ) and bone marrow-derived stem cells (Sera et al., 2009 ${ }^{16)}$.

Why did fatty degeneration occur without muscle regeneration? Uezumi and coworkers have demonstrated that whether skeletal muscle regenerates or fatty degeneration occurs depends on the type of stimulus (Uezumi et al., 2010 ${ }^{10)}$ ). When cardiotoxin was injected into the tibialis anterior muscle of $\mathrm{C} 57 \mathrm{BL} / 6$ mice, it caused damage to the muscle tissue, with subsequent muscle regeneration and no fatty degeneration. In contrast to cardiotoxin injection, glycerol injection injured the muscle tissue, followed by fatty degeneration. This fatty degeneration was attributed to adipocytes derived from the PDGFR $\alpha^{+}$cells present in the muscle tissue. Also, in the glycerol-treated muscle, the proliferation of myogenic progenitors, or satellite cells, was suppressed.
The molecular basis of this mechanism remained to be elucidated. In the present study, evidence of muscle regeneration, e.g., the emergence of myotubular cells, was not found. The origin of these adipocytes might be mesenchymal progenitors in muscle tissue.

In the present case, the reason why the sartorius muscles underwent the strongest fatty degeneration is unknown. Further studies are necessary to shed light on this issue.

In conclusion, we described a rare case in which skeletal muscle tissue was replaced by fat to an extreme degree. This fat accumulation was ascribed to fatty degeneration, or adipocyte replacement, following muscle damage. It is conceivable that the muscle damage was induced by endocrine and metabolic disorders.

\section{Acknowledgments}

The authors would like to express their gratitude to Masahiro Miura, Ph.D. for his helpful discussion and critical comments, and to Ms. Yukari Goto for her excellent secretarial assistance.

\section{References}

1) Virkamaki A, Korsheninnikova E, Seppala-Lindroos A, Vehkavaara S, Goto T, Halavaara J, Hakkinen A-M and Yki-Jarvinen H. Intramyocellular lipid is associated with resistance to in vivo insulin actions on glucose uptake, antilipolysis, and early insulin signaling pathways in human skeletal muscle. Diabetes 2001; 50: 2337-2343.

2) Goodpaster BH and Wolf D. Skeletal muscle lipid accumulation in obesity, insulin resistance, and type 2 diabetes. Pediatric Diabetes 2004; 5:219-226.

3) Hamano $T$, Mutoh $T$, Hirayama M, Kawamura Y, Nagata M, Fujiyama $\mathrm{J}$ and Kuriyama. Muscle MRI findings of X-linked spinal and bulbar muscle atrophy. J Neurol Sci 2004; 222:93-97.

4) Dulor J-P, Cambon B, Vigneron P, Reyne Y, Nougues J, Casteilla $\mathrm{L}$ and Bacou F. Expression of specific white adipose tissue genes in denervation-induced skeletal muscle fatty degeneration. FEBS Letters 1998; 439:89-92.

5) Banker BQ and Engel AG. Basic reactions of muscle. In: Myology. Engel A.G. and Franzini-Armstrong C. (eds). McGraw-Hill. New York. 2004; 1:691-747.

6) Olsen DB, Langkilde AR, Orngreen MC, Rostrup E, Schwartz M and Vissing J. Muscle structural changes in mitochondrial myopathy relate to genotype. J Neurol 2003; 250:1328-1334.

7) Khaleeli AA, Griffith DG and Edwards RH. The clinical presentation of hypothyroid myopathy and its relationship to abnormalities in structure and function of skeletal muscle. Clin Endocrinol 1983; 19:365-376.

8) Bailey JL, Wang X, England BK, Price SR, Ding X and Mitch WE. The acidosis of chronic renal failure activates muscle proteolysis in rats by augmenting transcription of genes encoding proteins of the ATP- dependent ubiquitin- proteasome pathway. J Clin Invest 1996; 97:1447-1453.

9) Merforth S, Osmers A and Dahlmann B. Alterations of proteasome activities in skeletal muscle tissue of diabetic rats. Mol Biol Rep 1999; 26:83-87.

10) Uezumi A, Fukada S, Yamamoto N, Takeda S and Tsuchida K. 
Mesenchymal progenitors distinct from satellite cells contribute to ectopic fat cell formation in skeletal muscle. Nature Cell Biol 2010; 12:143-152.

11) Visser M, Goodpaster BH, Krtchevsky SB, Newman AB, Nevitt M, Rubin SM, Simonsick EM and Harris TB. Muscle mass, muscle strength, and muscle fat infiltration as predictors of incident mobility limitations in well-functioning older persons. $\mathrm{J}$ Gerontol A Biol Sci Med Sci 2005; 60:324-333.

12) Joe AWB, Yi L, Natarajan A, Grand FL, So L, Wang J, Rudnicki MA and Rossi FMV. Muscle injury activates resident fibro/adipogenic progenitors that facilitate myogenesis. Nature Cell Biol 2010; 12:153-163.

13) Farrington-Rock C, Crofts NJ, Doherty MJ, Ashton BA, Griffin-
Jones $\mathrm{C}$ and Canfield AE. Chondrogenic and adipogenic potential of microvascular pericytes. Circulation 2004; 110:2226-2232.

14) Yamanouchi $K$, Yada $E$, Ishiguro $N$, Hosoyama $T$ and Nishihara M. Increased adipogenicity of cells from regenerating skeletal muscle. Exp Cell Res 2006; 312:2701-2711.

15) Xaymardan M, Gibbins JR and Zoellner H. Adipogenic healing in adult mice by implantation of hollow devices in muscle. Anat Rec 2002; 267:28-36.

16) Sera $Y$, Larue AC, Moussa O, Mehrotra M, Duncan JD, Williams CR, Nishimoto E, Schulte BA, Watson PM, Watson DK and Ogawa M. Hematopoietic stem cell origin of adipocytes. Exp Hematol 2009; 37:1108-1120. 